https://doi.org/10.15407/ufm.21.02.153

\author{
E.A. TSAPKO * and I.Ye. GALSTIAN ** \\ G.V. Kurdyumov Institute for Metal Physics of the NAS of Ukraine, \\ 36 Academician Vernadsky Blvd., \\ UA-03142 Kyiv, Ukraine \\ *tsapkoe@gmail.com, ** stenforti@ukr.net
}

\title{
POSITRON SPECTROSCOPY STUDY OF STRUCTURAL DEFECTS AND ELECTRONIC PROPERTIES OF CARBON NANOTUBES
}

The advantages and restrictions of different positron spectroscopy methods in the study of electronic properties of multilayer carbon nanotubes (MWCNTs) with metallic and semiconductor types of conductivity are considered. The defects' influence on the parameters of the MWCNTs' electronic structure is established via method of the angular correlation of annihilation radiation (ACAR). Analysis of the results shows that annihilation occurs with both $\sigma$-electrons (within the interlayer intervals), quasi-free electrons, and electrons of unsaturated covalent bonds. As determined, the increase in the defects' concentration results to an increase in the radius of localization of the electron wave function $\left(r_{m 1}\right)$ within the interlayer intervals and to an increase in the quasi-free electron concentration. Due to the formation of edge dislocations in the MWCNTs, the doubling of $r_{m 1}$ (up to $0.25 \mathrm{~nm}$ ), the hybridization of unsaturated and stretched $\sigma$-bonds, and, as a consequence, the increase of the concentration of conduction electrons occurs. The high sensitivity of the positrons to defects can be used to develop methods of MWCNTs' attestation and defect identification; the $2 r_{m b}, 2 r_{m i}$, and $R$ values obtained from the ACAR spectra are the thickness of the layer, the interlayer distance, and the effective radius of free volume of the MWCNTs, respectively.

Keywords: positron spectroscopy, carbon nanotubes, structural defects, wave-function localization radius, electronic properties.

\section{Introduction}

Positron, as the antiparticle of an electron, was predicted by Dirac in 1930 [1] and discovered by Anderson in 1933 [2]. Positronium (Ps), the binding state of a positron and an electron, is the lightest atom (with a

Citation: E.A. Tsapko and I.Ye. Galstian, Positron Spectroscopy Study of Structural Defects and Electronic Properties of Carbon Nanotubes, Progress in Physics of Metals, 21, No. 2: 153-179 (2020) 
radius of $0.106 \mathrm{~nm}$ and ionization energy of $6.77 \mathrm{eV}$ ), was observed in gases by Deutsche in 1951 [3]. After these discoveries, it became clear that such parameters of the positron spectroscopy (PS) as the positrons' lifetime (LTP) and the spectrum profile parameters of the angular correlation of annihilation radiation (ACAR) [4-6] are related to the integrals of positron and electronic wave functions, parameters of fine electronic structure of the studied objects. In recent years, the PS has been successfully used to study the properties of free volume of pores and layers in graphene, single- and multilayer carbon nanotubes (MWCNTs) [7-10]. The key aspect of using the PS is the fact that the positron and Ps are localized in the defects, which previously existed in the sampling material, as well as in pores of free volume $(\approx 0.106-1 \mathrm{~nm})$ and voids $(>1 \mathrm{~nm})$ [11-15]. There are three mutually complementary methods of the PS: ACAR, lifetime of positron (LTP), and Doppler broadening of the annihilation line (DBAL).

\section{Positron Spectroscopy Methods}

\subsection{Angular Correlation Spectroscopy of Annihilation Radiation}

A positron with a kinetic energy of $0.51 \mathrm{MeV}$, entering the sample, is thermalized (it comes into thermal equilibrium with the lattice) and, having an average thermal velocity (corresponding to $k T=0.002 \mathrm{Ry}$ ), it annihilates with the electrons of the sample. This technique considers only those processes of annihilation of a positron with an electron, in which two $\gamma$-quanta with energies of $0.51 \mathrm{MeV}$ are generated with scattering at an angle $2 \pi$ in the case of a zero momentum of the annihilating pair. In the presence of a nonzero momentum, the spreading angle of $\gamma$-quantum differs from $2 \pi$ by a value of $\theta$ that is proportional to their momentum. Because the average thermal positron momentum is constant, and the electrons in the sample are distributed over the momenta, the dependence of the intensity of the detected $\gamma$-quanta on the angle $\theta$ corresponds to this distribution (Fig. 1).

The angular correlation of annihilation radiation spectra are measured in the angle ranges from $-35 \mathrm{mrad}$ to $35 \mathrm{mrad}$ by means of the annihilation spectrometer with a long-slit geometry, an angular resolution of $1.07 \mathrm{mrad}$, and a ratio of background intensity to peak intensity up to $5 \%$. For interpretation of experimental data, we used the classical analytical representation of the ACAR spectra in the form of the sum of three terms. They are as follow: (i) the parabolic part due to the annihilation of positrons with free electrons, (ii) two Gaussian parts due to the annihilation of positrons with core electrons of different types of cores, and (iii) an ultra-narrow Gaussian part (with dispersion from $0.15 \mathrm{mrad}$ to $0.9 \mathrm{mrad}$ ) due to annihilation 'on the catch' from the state of ortho- 


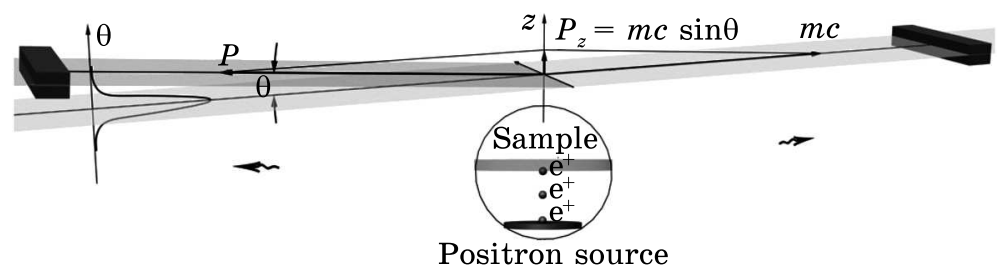

Fig. 1. Sketch of the angular correlation spectrometer of annihilation radiation [6]

positronium (o-Ps) [16-18]:

$$
\begin{gathered}
I^{\text {theor }}(\theta)=I_{P}\left[\frac{\theta_{F}^{2}-\theta^{2}}{2}+A_{B} T \ln \left(1+\exp \left\{-\frac{\theta_{F}^{2}-\theta^{2}}{2 A_{B} T}\right\}\right)\right]+ \\
+\sum_{j=1}^{3} \frac{I_{G}^{j}}{\sigma_{j} \sqrt{2 \pi}} \exp \left\{-\frac{\theta^{2}}{2 \sigma_{j}^{2}}\right\} ;
\end{gathered}
$$

here, $\theta$ is the difference between the scattering angle of the annihilation gamma-ray quanta and $2 \pi, I^{\text {theor }}(\theta)$ is the analytical expression of the ACAR; $I_{P}, I_{G}^{j}$ are the amplitude coefficients (intensities) of the parabolic and Gaussian parts of the spectra, respectively; $\sigma_{j}$ are the Gaussian dispersions, $\theta_{F}$ is the angle corresponding to the Fermi momentum, $A_{B}$ is the renormalized Boltzmann constant, and $\mathrm{T}$ is the temperature of the sample.

To approximate experimental ACAR, the classical method of $\chi^{2}$-minimum [19] was used as part of the standard product based on the considerations, which follow below:

- statistics at the peak was not less than 10000 , therefore, the measurement errors obey the law of large numbers and are distributed normally;

- with the maximum number of spectrum components (parabola and 3 Gaussians), the number of fitting parameters is $n=11$, and, with the number of experimental points in the spectrum, $N$, of the order of 200 , the number of free parameters, $M=N-n$, is greater than 10, and composite function (4) tends to the distribution ' $\chi^{2}$ ' with zero mean and unit variance [19],

$$
\chi^{2}=\sum_{i=1}^{N} \frac{\left[I^{\exp }\left(\theta_{i}\right)-I^{\mathrm{app}}\left(\theta_{i}\right)\right]^{2}}{2 I^{\exp }\left(\theta_{i}\right)},
$$

where $N$ is the number of experimental points in the spectrum, $I^{\exp }\left(\theta_{i}\right)$ are the experimentally measured intensities, $I^{\mathrm{app}}\left(\theta_{i}\right)$ are the convolutions of the 'true' spectrum (1) with the resolution function (RF) of the spectrometer, which is presented in the form of a Gaussian [19], 


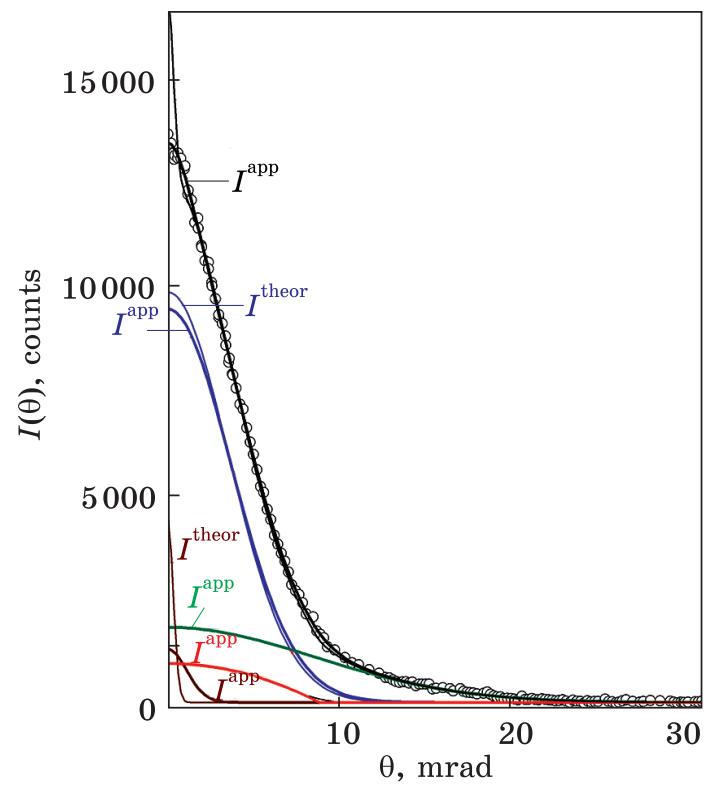

$P_{F}=m c \theta_{F}$,

Fig. 2. Decomposition of the ACAR spectrum of a Teflon $3+0.5$ wt. $\%$ multilayer carbon nanotube composite into 4 components, parabolic (thick black) and 3 Gaussian components

$$
R(\theta)=\frac{1}{\sigma_{r} \sqrt{2 \pi}} \exp \left(-\frac{\theta^{2}}{2 \sigma_{r}^{2}}\right),
$$

where $\sigma_{r}=1.07 \mathrm{mrad}$ is dispersion of the resolution function or angular resolution of the spectrometer.

From the ACAR spectra, we obtain the Fermi momentum, $P_{F}$, related to the angle $\theta_{F}$ by the following equation [19]:

where $m$ is the rest mass of an electron, $c$ is the velocity of light.

Taking integral of the parabolic part and the full spectrum of the ACAR over the corners, we obtain the probability of annihilation of positrons with free electrons $P_{\theta_{F}}$ as the ratio of the area under the parabolic part to the total area under the ACAR.

The Gaussian contributions to the ACAR are due to the annihilation of positrons with bound electrons of dangling bond defects such as vacancies in polymers and carbon nanotubes (CNTs) (Eq. (1)) and core electrons, i.e. electrons with large momenta (Eq. (2)).

The dispersions $\sigma_{j}$ of these Gaussians determine the widths of the momentum $j$ distributions of electrons, which are inversely proportional to the widths of their spatial distribution, and relate to the distance $r_{m}$ from the centre of the Wigner-Seitz cell (on which the overlap of the wave functions of the annihilating positron and electron is maximum) as $[20,21]$

$$
r_{m_{j}}=\sqrt{3 / 2} \frac{\hbar}{m c \sigma_{j}}
$$

where $m$ is the rest mass of an electron, $c$ is the velocity of light, $\hbar$ is the Planck constant.

The probabilities of annihilation of positrons with bound electrons $P_{r_{m_{j}}}$ are defined as the ratio of the areas under the corresponding components to the area under the full spectrum of the ACAR.

Molecular dynamics in polymer composites requires the existence of free volumes, i.e. nanoscale defects from 0.1 to several nanometers [22]. 
In accordance with the Tao model [23], the free volume is represented as a sphere of radius $R$ with a homogeneous electron layer of thickness $\Delta R$ on its surface and is associated with the dispersion of the ultranarrow component of the ACAR (the narrowest component in Fig. 2) by a simple relation:

$$
R=\frac{0.7049}{\sigma_{3}}-0.1656[\mathrm{~nm}]
$$

Accordingly, the probability of positron annihilation in pores from the o-Ps state (pick-off annihilation) is also calculated.

The next important stage in the development of the PS was the creation of the two-dimensional method of the ACAR (2D-ACAR). Particularly interesting results in accordance with this method were obtained in highly anisotropic layered structures of high-temperature superconductors $[24,25]$ that made it a direct experimental method for testing theoretical models of solids [26]. Despite the outstanding results in the study of $2 D$-shapes of free volumes in oriented polymer materials, there are a number of restrictions on the use of the $2 D$-ACAR in complex polymer systems. These restrictions are because a good experiment takes several days, and all this time, the sample is irradiated with a powerful source of positrons $(>20 \mathrm{mCi})$ that can lead to the radiation damage [22].

\subsection{Doppler Broadening of the Annihilation Line Spectroscopy}

The DBAL technique, like the ACAR, is based on the fact that the momentum of the annihilating pair is carried away by two $\gamma$-quanta, and the blurring of the photopeak of $511 \mathrm{keV}$ is due to the distribution of the annihilating electrons over the momenta.

By hardware, the technique is quite simple, and the DBAL spectrum registration is much faster than ACAR spectra, however, there are significant limitations. The DBAL spectra are recorded using energy-sensitive GeLi detectors, which should always be at liquid nitrogen temperature. Due to the limited energy resolution of GeLi crystals, the DBAL spectra cannot be decomposed into components, like the ACAR spectra, and their shape can be estimated only qualitatively by integrated parameters.

In two-photon processes of positron annihilation due to the laws of conservations of energy and momentum, the energy of annihilation photons is shifted by $\Delta E[14]$ :

$$
\Delta E= \pm p \frac{c}{2}
$$

where $c$ is the velocity of light, $p$ is the component of the electron mo- 


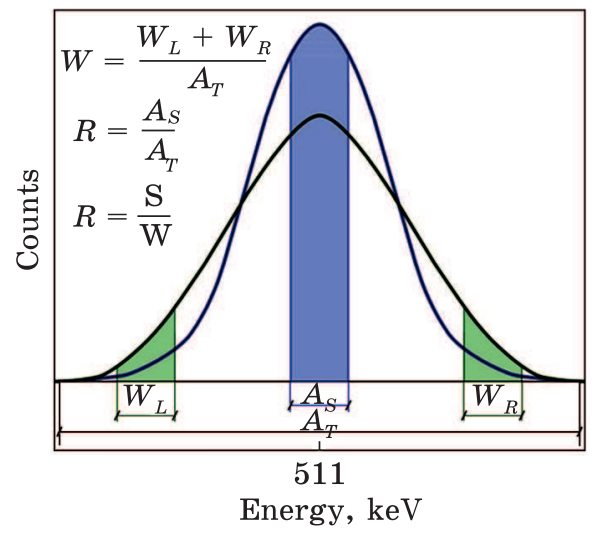

Fig. 3. Doppler broadening of the $511 \mathrm{keV}$ annihilation line [7]

mentum in the direction of photon emission. In the energy spectrum of annihilation radiation, these shifts lead to Doppler broadening of the photopeak with energy of $511 \mathrm{keV}$, which is quantitatively determined by the line shape parameters. They are the $S$ parameter as the ratio of the area under the central peak $A_{S}$ to the total area under the full $A_{T}$ curve, and the $W$ parameter as the ratio of the area under the wings, $W_{L}+W_{R}$, to the full area of the $A_{T}$ peak, as shown in Fig. 3.

As can be seen from Fig. 3, the $S$ parameter is sensitive to changes in the low-energy region of the DBAL and corresponds to the annihilation of positrons with free and almost free electrons. The $W$ parameter is sensitive to changes in the high-energy region of the DBAL and is due to the annihilation of positrons with high-energy core electrons [27]:

$$
S=A_{S} / A_{T}, W=\left(W_{L}+W_{R}\right) / A_{T}, \quad R=S / W .
$$

The DBAL technique was further developed in Refs. $[14,22,28$, 29], where the issues of molecular dynamics and free volume properties were studied using the two-dimensional DBAL (2D-DBAL).

\subsection{Lifetime Positrons Spectroscopy}

The lifetime of positron (LTP) $\tau$ is a function of the electron density in the annihilation region. The annihilation rate $\lambda$ of thermalized positrons, which is the inverse of the positron lifetime, $\tau$, is determined by the overlapping of the positron density $n_{+}(\mathbf{r})=\left|\psi_{+}(\mathbf{r})\right|^{2}$ and the electron density $n_{-}(\mathbf{r})[28]$ :

$$
\lambda=\frac{1}{\tau}=\pi r_{0}^{2} c \int\left|\psi_{+}(\mathbf{r})\right|^{2} n_{-}(\mathbf{r}) \gamma d \mathbf{r},
$$

where $r_{0}$ is the classic radius of the electron, $\mathbf{r}$ is the spatial coordinate. The correlation function $\gamma=\gamma\left\{n_{-}(\mathbf{r})\right\}=1+\Delta n_{-} / n_{-}$describes an increase in $\Delta n$, i.e. electron density due to the Coulomb attraction between the positron and the electron. This effect is called electron density enhancement near the positron ('enhancement' factor). In principle, the correlation function can be written as [30]:

$$
\gamma\left\{n_{-}(\mathbf{r})\right\}=1+\pi v_{0} / v,
$$

where $v_{0}=e^{2} / \hbar$ is the Bohr velocity, $v$ is the electron velocity. The core 
electrons usually have velocities much higher than $v_{0}$; therefore, the increase in the density of core electrons near the positron is small. In exact band calculations [31,32], where an electron is embedded into a system of electrons, which are strongly connected with the nucleus, it was found that the increase in the electron density near the positron is very similar to the result for one free electron, but slightly reduced in magnitude mainly due to Pauli principle. The obtained quantitative estimations of the enhancement of the core contribution to both the total and momentum-dependent annihilation rates turned out to be significantly lower as compared to those assumed within the framework of the semi-empirical estimations [32]. The positron-free electron annihilation rates calculated in accordance with the model of independent particles are in perfect agreement with experiment [30].

The main feature of all methods of electron-positron annihilation (EPA) is the increased sensitivity of positrons to local features of the electron density $n_{-}(\mathbf{r})$, for example, to vacancies in metals [7, 33-36]. Despite the fact that the density of free electrons in vacancies in metals is approximately by $20 \%$ lower than in an ideal crystal [7], positrons are captured by vacancies, because, in them, there is not only a positively charged core, but also the vacancy volume, as a rule, less than the volume of the Wigner-Seitz cell [37]. The situation is substantially complicated even in the simplest case of disordered binary substitutional alloys (DBA) where, unlike vacancies, for the formation of the bound state of the positron, there are no sufficiently large capture potentials in the cells occupied by impurity atoms. The notion of the predominant affinity of positrons (affinities) $f_{A}$ for impurity atoms (an increased probability of positron annihilation in cells occupied by impurity atoms) was introduced in Refs. [38-40]. The pseudopotential differences were calculated for a number of alloys [40], and it was found that the positron could have a strong affinity for one type of alloy atoms. However, at least, the goal of getting qualitative agreement with the experiment within the framework of the models [38-40] with real pseudopotential differences $\left(\Delta V_{A}=-0.08 \mathrm{Ry}\right)$ in cells occupied by atoms of different types was failed.

In work [41], in accordance with the free-particle model (FPM), the momentum and spatial distributions of positrons were calculated within the coherent potential approximation (CPA). It was established that, even with simplified assumptions about the constant difference in atomic potentials $\Delta V_{A}$ in cells occupied by atoms of different types, one could quantitatively describe both the increased affinity of positrons $f_{A}$ to impurity atoms and the broadening of the ACAR spectra.

In paper [42], within the framework of the FPM in the CPA with a constant atomic potential difference $\Delta V_{A}=-0.1$ Ry (taken from [43]) in 
the cells occupied by the $\mathrm{In}$ and $\mathrm{Pb}$ atoms, the density of states of free electrons in energy over the entire concentration range was calculated.

It has been revealed that, at the boundary of the first Brillouin zone, the calculated density of states has a singularity and lies below the Sommerfeld's one that leads to integration to higher energies when determining the Fermi energy. The calculation results are in a good numerical agreement with the experimental dependence of the Fermi momentum on the concentration for the $\mathrm{In}_{c} \mathrm{~Pb}_{1-c}$ system [38]. Therefore, the Fermi energy value for the $\operatorname{In}_{c} \mathrm{~Pb}_{1-c}$ alloy is much higher than in each of the pure components and is due precisely to the electronic structure of the alloy, but it is not due to the increased affinity $f_{\mathrm{Pb}}$ of the positrons to lead atoms.

To explain the increased affinity of positrons to $\mathrm{Li}$ atoms in $\mathrm{Li}_{c} \mathrm{Mg}_{1-c}$ [39] alloys, the potentials necessary [44] for the formation of a bound positron state on $\mathrm{Li}$ atoms in $\mathrm{Li}_{c} \mathrm{Mg}_{1-c}$ alloys were estimated (within the framework of one-, two- and three-site CPA in the FPM). In the 1-CPA, for the formation of the bound state of a positron in cells occupied by $\mathrm{Li}$ atoms in pure $\mathrm{Mg}$, as in [41], it was as follows:

$$
\Delta V_{1-\mathrm{CPA}}^{\mathrm{Li}}=-k_{0}^{2} / 3=-0.175 \mathrm{Ry},
$$

where $k_{0}$ is the electron momentum on the surface of a sphere equal to the volume of the Brillouin zone. In the 2-CPA, for the formation of the bound state of a positron at two neighbouring sites of the crystal lattice occupied by $\mathrm{Li}$ atoms in pure $\mathrm{Mg}$, the value of the capturing potential is equal to [41]:

$$
\Delta V_{2-\mathrm{CPA}}^{\mathrm{Li}}=-\frac{1}{3} k_{0}^{2}\left(1+\frac{v_{a} k_{0}^{2}}{6 \pi^{2}} \frac{1}{l} \mathrm{Si}\left(k_{0} l\right)\right)^{-1}=-0.127 \mathrm{Ry},
$$

where $v_{a}$ is the volume of the sphere equal to the volume of the WignerSeitz cell, $l$ is the distance between the sites of the crystal lattice of the alloy, and $\operatorname{Si}\left(k_{0} l\right)$ is the integral sine. In the 3-CPA, for the formation of the bound state of the positron at three neighbouring sites of the crystal lattice occupied by $\mathrm{Li}$ atoms in pure $\mathrm{Mg}$, the value of the capturing potential is found from the equation [41]

$$
\begin{gathered}
\left\{1+\frac{3}{k_{0}^{2}} \Delta V\right\}^{3}-(\Delta V)^{2}\left\{\frac{v_{a}}{2 \pi} \frac{1}{l} \operatorname{Si}\left(k_{0} l\right)\right\}^{2} \times \\
\times\left\{1+\frac{3}{k_{0}^{2}} \Delta V\left[1-\frac{v_{a} k_{0}^{2}}{3 \pi^{2}} \frac{1}{l} \operatorname{Si}\left(k_{0} l\right)\right]\right\}^{3}=0, \\
\Delta V_{3-\mathrm{CPA}}^{\mathrm{Li}}=-0.093 \mathrm{Ry},
\end{gathered}
$$

Summing up, we can say that, with an increase in the number of particles in a cluster, the absolute value of the capturing potential de- 


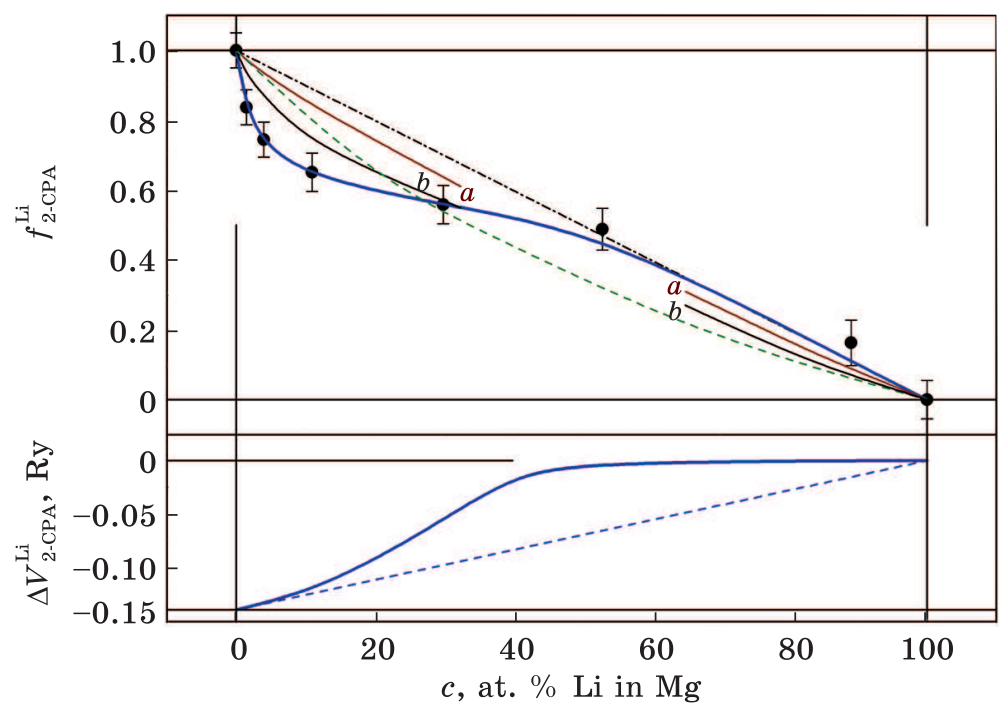

Fig. 4. Lithium concentration dependences of the reduced core annihilation rate $f_{2-\mathrm{CPA}}^{\mathrm{Li}}$ [39] and the constant positron pseudopotential $\Delta V_{2-\mathrm{CPA}}^{\mathrm{Li}}$ [44] in cells occupied by $\mathrm{Li}$ atoms in $\mathrm{Li}_{c} \mathrm{Mg}_{1-c}$ alloys, where $\Delta V_{2 \text {-CPA }}^{\mathrm{Li}}$ were chosen [44] so that the $f_{2-\mathrm{CPA}}^{\mathrm{Li}}$ values calculated in 2-CPA in the FPM coincided with the cited core annihilation rates [39]

creases, and $\Delta V_{3-\mathrm{CPA}}^{\mathrm{Li}}$ is significantly closer to $-0.08 \mathrm{Ry}$ estimated in [40]. From the above $\Delta V^{\mathrm{Li}}$ for 1-, 2-, and 3-CPA, one can evaluate the influence of states localized in large clusters of attracting atoms on the formation of the density of states of positrons near the bottom of the band (band tailing).

The concentration dependences of density are calculated within the framework of the 2-CPA in the FPM of positron states near the bottom of the band (at $\Delta V_{2-\mathrm{CPA}}^{\mathrm{Li}}=-0.14 \mathrm{Ry}$ ) at low Li concentrations. These calculated concentration dependences have a split-off band, which expands with increasing Li concentration, merging with the ground one, and further resonances go deeper into the band, while in the 1-CPA with the same $\Delta V_{1-\mathrm{CPA}}^{\mathrm{Li}}=-0.14 \mathrm{Ry}$, no features are observed, and the bottom of the zone in the 1-CPA is always significantly higher than in the 2-CPA. Figure 4 shows the dependence of $\Delta V_{2-\mathrm{CPA}}^{\mathrm{Li}}$ on the Li concentration in $\mathrm{Li}_{c} \mathrm{Mg}_{1-c}$ alloys, at which the affinity of positrons calculated in the 2-CPA in the FPM for $\mathrm{Li}$ atoms ( $f_{2-\mathrm{CPA}}^{\mathrm{Li}}$ ) coincides with experimental one from Ref. [39]. The dependence $\Delta V_{2 \text {-CPA }}^{\mathrm{Li}}$ on the Li concentration should not be interpreted as charge transfer between cells, but rather as, in terms of Ref. [45], the bottom of the lowest positron energy region relative to the total (precisely defined reference energy of the main ma- 
trix). It is clear that, with an increase in the $\mathrm{Li}$ concentration in $\mathrm{Li}_{c} \mathrm{Mg}_{1-c}$ alloys, the level of the matrix support energy will drop and, accordingly, decrease in absolute value, $\Delta V_{\mathrm{CPA}}^{\mathrm{Li}}$.

The processes of positron annihilation were not considered in [41, $42,44]$, where possible positron states near the bottom of the zone were calculated as consistent with the first principles, and since the thermal energy of the positron is quite low, of the order of $k T=0.002 \mathrm{Ry}$, it is located close to the bottom of the zone. Perhaps, these states in the split-off zones are so rare that the positron does not have time to occupy them during its lifetime. This may be the subject of further research, but for now, we will focus on the study of complex heterostructures constructed from different materials. We will interpret the affinity of positrons for the individual components of these structures as objects, which form the bottom of the lowest positron energy zone, including split bands and resonances, relative to the total, precisely determined reference energy of the matrix [45].

\subsubsection{Basics of the Experiment LTP}

During the decay of ${ }^{22} \mathrm{Na}$, a quantum with energy of $1.27 \mathrm{MeV}$ is emitted together with the production of a positron. During thermalization (a few picoseconds), the positron penetrates the sample to a depth of $0.1 \mathrm{~mm}$ and diffuses in it up to $100 \mathrm{~nm}$. The lifetime of an individual positron is the time between registration of a $\gamma$-ray with an energy of 1.27 MeV (birth of a positron) and registration of a $\gamma$-quantum with an energy of $0.511 \mathrm{MeV}$ (annihilation of a positron). The source activity should be sufficiently low $(5-10 \mu \mathrm{Ci})$, so that on average each only one positron was located in the sample, and there was no mixing of the initial and final quanta occurring from various annihilation events.

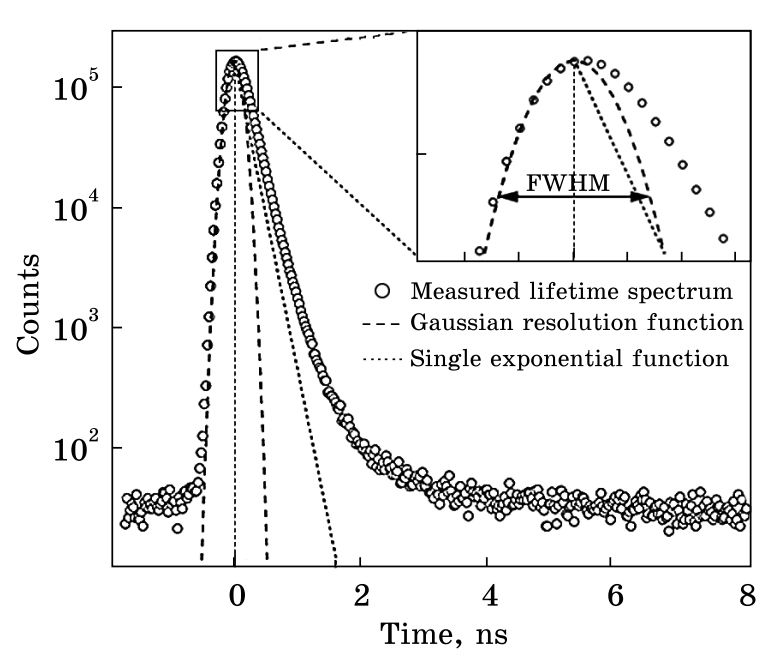

A sample-source-sample sandwich is clamped between two detectors and, unlike the ACAR, all positrons fall into the samples and $\gamma$-quanta fall into the detectors, where, using energy-sensitive scintillators and photomultipliers, they are converted into analogue pulses of

Fig. 5. One-component spectrum of the positron lifetime [7] 
different amplitudes. The discriminator in terms of momentum from a $\gamma$-quantum with energy of $1.27 \mathrm{MeV}$ opens the circuit, and the momentum from a $\gamma$-quantum with energy of $0.511 \mathrm{MeV}$ closes the circuit. The time between the opening and closing of the circuit is remembered as one act of annihilation of a positron with such a lifetime, and the process is repeated approximately $10^{6}-10^{7}$ times. The time between the opening and closing of the circuit is quantized by the channel width, and the entire spectrum is delayed by the delay line to the 'zero' time $t_{0}$. The temporal resolution of the spectrometer is mainly determined by the scintillator-photomultiplier, and it ranges from $180 \mathrm{ps}$ to $280 \mathrm{ps}$ that makes it possible to measure the LTP with an accuracy of about 1 ps and resolve it as different components of the LTP, if they differ by more than $50 \mathrm{ps}$.

\subsubsection{Processing of LTP Spectra}

The time-dependent decay spectrum of positrons $D(t)$ in the sample is defined as [48]

$$
D(t)=\sum_{i=1}^{k+1} I_{i} \exp \left(\frac{t-t_{0}}{\tau_{i}}\right),
$$

where $k$ is the number of positron annihilation centres characterized by their individual lifetimes $\tau_{i}$ and their intensities $I_{i}$. One more contribution is the positron annihilation in the source $(k+1)$.

The spectrum of the positron lifetime $N(t)$ is the absolute value of the time derivative from the positron decay spectrum $D(t)$ [48]:

$$
N(t)=\sum_{i=1}^{k+1} \frac{I_{i}}{\tau_{i}} \exp \left(-\frac{t-t_{0}}{\tau_{i}}\right)
$$

The processing of the LTP spectra is carried out according to the same procedure as the ACAR with various resolution functions [46-49], the simplest of which is Gaussian [46]:

$$
R(t)=\frac{1}{\sigma \sqrt{2 \pi}} \exp \left(-\frac{\left(t-t_{0}\right)^{2}}{2 \sigma^{2}}\right) .
$$

For Gaussian-shaped scintillators with a good energy resolution (17), the RFs are quite sufficient, although in Ref. [47], the RFs were presented as two-component with the purpose of independent determination of the background constant from the area to the left of $t_{0}$ (Fig. 5), where there are no decay components. More complex forms of the RF were proposed in Ref. [47], however, the single-component (17) RF remained classic [49]. 


\section{Sensitivity of Positron Spectroscopy \\ Method o the Electronic Structure and Properties of Carbon Nanotubes}

A specific feature of the atomic structure of nanostructured materials is that each of their elements (graphene, nanotube, fullerene, cluster, nanopore, etc.), in addition to the atomic structure, has a specific local structure of free volumes. Moreover, we can study their electronic strucure exactly within the framework of the PS. The interest in such objects is primarily because they do not have exact analogues in three-dimensional systems, and a number of phenomena, which have wide prospects of application, characterize them, in particular, such as high electron mobility in carbon nanotubes, effective absorption of microwave (MWR) and infrared (IR) radiation, etc.

In article [50], within the local density approximation, authors revealed that for the actually observed diameters of multilayer CNTs (MWCNTs), the positron density differs from zero only in the first interlayer space. Consequently, in ideal defect-free MWCNTs, positrons annihilate between the outer two layers (the penultimate and last ones). The LTP calculated in Ref. [50] approximately coincide with those obtained experimentally in Refs. [51, 52]; but the experimental LTP spectra turned out to be 3-component. As can be seen from Tables 1 and 2, the positron lifetimes obtained by different authors under different synthesis conditions are component-wise within the same limits approximately coinciding with those predicted in Ref. [50].

Table 1. Positron lifetimes and MWCNT diameters [51]

\begin{tabular}{|l|c|c|c|c|c|c|c|}
\hline No. of sample & $\tau_{1}, \mathrm{~ns}$ & $\tau_{2}, \mathrm{~ns}$ & $\tau_{3}, \mathrm{~ns}$ & $I_{1}, \%$ & $I_{2}, \%$ & $I_{3}, \%$ & Diameter, nm \\
\hline MWCNTs-1 & 0.216 & 0.385 & 2.619 & 38.100 & 61.001 & 0.896 & $60-90$ \\
MWCNTs-2 & 0.203 & 0.379 & 2.543 & 34.500 & 64.510 & 1.078 & $40-80$ \\
MWCNTs-3 & 0.218 & 0.381 & 2.808 & 40.900 & 58.202 & 0.968 & $50-90$ \\
MWCNTs-4 & 0.196 & 0.386 & 2.594 & 66.501 & 31.800 & 1.682 & \\
MWCNTs-5 & 0.229 & 0.424 & 3.322 & 60.904 & 37.501 & 1.565 & $80-100$ \\
MWCNTs-6 & 0.238 & 0.429 & 3.607 & 66.080 & 32.621 & 1.300 & \\
Coal & 0.290 & 0.818 & 3.682 & 90.890 & 7.110 & 1.998 & \\
\hline
\end{tabular}

Table 2. Positron lifetimes of MWCNTs

in powder (pow) and a compact (com) state [51]

\begin{tabular}{|l|c|c|c|c|c|c|c|}
\hline No. of sample & $\tau_{1}, \mathrm{~ns}$ & $\tau_{2}, \mathrm{~ns}$ & $\tau_{3}, \mathrm{~ns}$ & $I_{1}, \%$ & $I_{2}, \%$ & $I_{3}, \%$ & $\tau_{m}, \mathrm{~ns}$ \\
\hline CNT 1 pow & 0.219 & 0.392 & 2.150 & 21.3 & 78.4 & 0.24 & 0.360 \\
CNT 2 pow & 0.142 & 0.300 & 0.647 & 39.8 & 54.5 & 4.90 & 0.300 \\
CNT 2 com & 0.197 & 0.400 & 2.100 & 47.6 & 51.8 & 0.65 & 0.314 \\
\hline
\end{tabular}


The additional lifetime $\tau_{3}$, with an intensity of $1-2 \%$, which was not predicted in Ref. [50], is due to annihilation from the state of orthopositronium in free volume pores with an effective radius, according to Ref. [23], of the order of $0.35 \mathrm{~nm}$, which is 2 times larger than the interlayer distances in MWCNTs. Consequently, annihilation from the state of ortho-positronium occurs outside the MWCNT, in the intermediate (intertube) regions.

The first component of LTP, $\tau_{1}$, most likely, is due to the annihilation of positrons in the bulk of the nanotubes (bulk) as well as the corresponding component in coal $(0.290 \mathrm{~ns})$. The second component of LTP, $\tau_{2}$, is more suitable for annihilation of positrons in defects in MWCNTs, taking into account that the electron density in defects is lower than the density of $\pi$-electrons in the interlayer space. The third component of LTP, $\tau_{3}$, has an order of magnitude larger than the first two (which have very low intensities up to $2 \%$ ) due to the annihilation of positrons from the state of ortho-positronium in free volume pores. This point of view on the positron annihilation regions was presented in Ref. [53] when considering the ACAR in MWCNTs.

From accurate band calculations of MWCNTs [50], it is known that the positron density is nonzero only inside the CNTs and, in principle, the ACAR spectrum should consist of two components, namely, parabolic ( $\pi$-electrons) and Gaussian ( $\sigma$-electrons) ones. Indeed [53], the length of $\pi$-bonds in the $x z$ plane is longer than the length of $\sigma$-bonds in the same plane. In addition, the graphene layer of MWCNTs, which thickness is determined by the length of $\sigma$-bonds in the $x z$ plane, is effectively positively charged from the positron point of view, because, in this layer, there are carbon cores together with nuclei and only a part of $\pi$-electrons, i.e., the positron is located between two positively charged $\sigma$-tubes together with a part of almost free $\pi$-electrons and, accordingly, annihilates with almost free $\pi$-electrons and core $\sigma$-electrons. Experimentally, in a MWCNT, a three-component spectrum of the ACAR is observed [53] (Fig. 6) with a parabolic component and two Gaussian components, which are wide and medium.

The parabolic contribution to the ACAR (1) is due to the annihilation of positrons with quasi-free $\pi$-electrons and is characterized by the angle $\theta_{F}$ corresponding to the Fermi momentum. We have to note here that delocalized $\pi$-electrons are not a classical 'electron gas', but a gas of electrons with an effective mass much higher than the electron mass. This is because the infinite motion of a quasi-free $\pi$-electron is possible only along the axis of the MWCNTs, while, in the plane of the perpendicular section of the tube, it is limited by its dimensions due to the large effective masses $m_{x}$ and $m_{y}$ (of the order of six electron masses).

The wide component of the ACAR is caused by the annihilation of positrons with electrons of defects in the graphene layer. Indeed, upon 


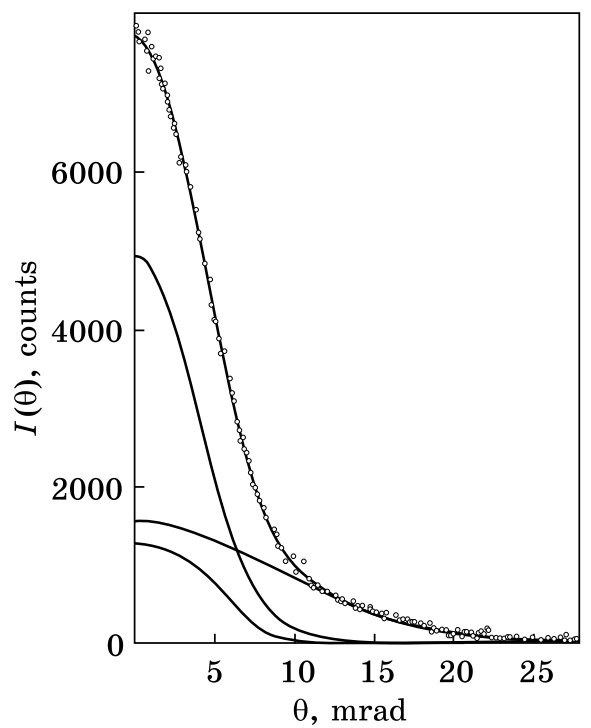

Fig. 6 . The characteristic spectrum of the ACAR in MWCNTs [53]

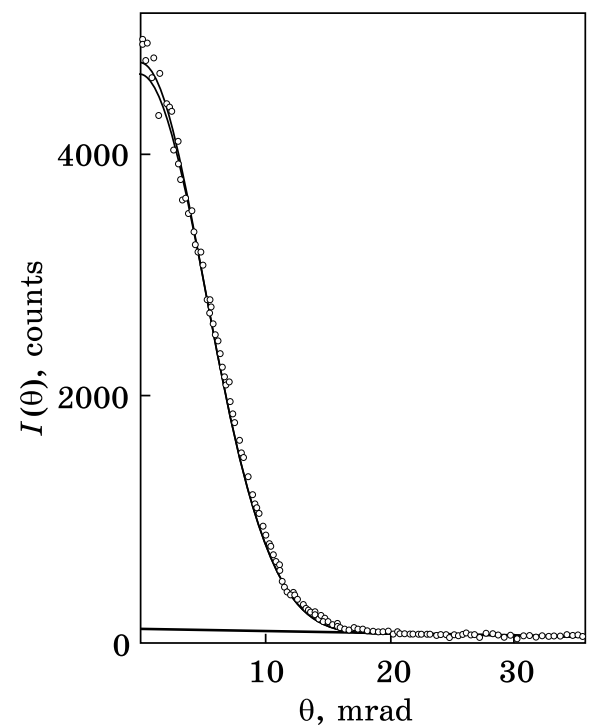

Fig. 7. The ACAR spectrum of semiconductor single-walled CNTs [53]

the formation of a vacancy in a graphene layer (positively charged from the positron point of view), a free volume is formed and filled with tails of the wave functions of the $\sigma$-tails of core and delocalized $\pi$-electrons. Although the electron density in this volume is low, it also does not have a repulsive potential of the nucleus; therefore, if the full effective charge of a vacancy is not sufficient for the formation of a bound state of a positron, then at least, it significantly increases the affinity of positrons for vacancies. The previously introduced annihilation parameter $r_{m b}$ (5) can be considered as the effective radius of the carbon core; however, the concept of the core, unlike the ionic and metallic ones, should be redefined as follows. The core electrons will be called all electrons that localized on the nucleus, with the exception of the quasi-free part of $\pi$-electrons, and accordingly obtained from the ACAR $2 r_{m b}$ value is the thickness of the MWCNT layer. We emphasize that it is possible to measure the wall thickness of MWCNTs within the framework of the PS only if there are vacancies in the wall.

A vacancy in MWCNTs leads to significantly larger distortions of the graphene layer than in crystalline graphite, but the total probability of positron capture by vacancies in crystalline graphite is higher than in CNTs. It can be caused by both a higher affinity of positrons for vacancies and simply a higher concentration of vacancies in crystalline graphite than in MWCNTs. This question can only be answered by the combined measurements of both the ACAR and the LTP. 
The value of $r_{m i}$ (5) obtained from the average width of Gaussian will be associated with the interlayer distance in the MWCNTs, i.e., $2 r_{m i}$ is the interlayer distance. The thickness of the graphene layer and the interlayer distance obtained from the ACAR numerically coincide with the corresponding values obtained from x-ray studies [54].

Figures 7-8 shows the ACAR spectra of semiconductor single-walled CNTs and the most defective multilayer CNTs, which contains edge dislocations.

The ACAR spectrum of semiconductor single-walled CNTs is a superposition of two Gaussians and does not contain a parabolic component, which indicates the absence of quasi-free electrons (Fig. 7). The latter is confirmed by a lower value of electrical conductivity $\sigma$ of the single-layer CNTs array as compared to multilayer CNTs. When packing CNTs in a direction perpendicular to their axis to a density of $0.7 \mathrm{~g} / \mathrm{cm}^{3}$, the electrical conductivity is of 0.4 and $8.0(\mathrm{Ohm} \cdot \mathrm{cm})^{-1}$ for single-layer and multilayer, respectively.

The spectrum of multilayer CNTs, in addition to two Gaussians, contains a parabolic component, a contribution to which was made by quasi-free electrons (Fig. 6). The value of this contribution for most of the studied MWCNTs, as well as for various modifications of graphite, is in the range from $12 \%$ to $15 \%$ [53]. In a separate series of MWCNT samples, record values of the parabolic contribution to the ACAR were observed (Table 3).

Other carbon nanotubes identified by electron microscopy were also used for the PS studies. Multilayer CNTs with a diameter of 10-20 nm of series No. 13 (Table 4) were obtained by the CVD (chemical vapour deposition) method and were purified from mineral impurities and other forms of carbon. The purity of nanotubes, according to TEM, is of 90$95 \%$, the specific surface is of $340 \mathrm{~m}^{2} / \mathrm{g}$. Single-walled semiconductor CNTs with a diameter of $1.4-1.6 \mathrm{~nm}$ were obtained by electric arc evaporation in the presence of a Ni/Y catalyst. The purification was conducted out by oxidation in air, the content of CNTs was of $99 \%$, and the external specific surface was of $375 \mathrm{~m}^{2} / \mathrm{g}$.

The bulk spiral MWCNTs with a diameter of about $200 \mathrm{~nm}$ were obtained by the electric arc method. The direct multilayer carbon nanotu-

Table 3. Results of decoding the parameters of the ACAR spectra of CNT_U Series [53]

\begin{tabular}{|c|c|c|c|c|c|c|}
\hline Sample & $\theta_{F}, \operatorname{mrad}$ & $P_{\theta_{F}}, \%$ & $r_{m b}, \mathrm{~nm}$ & $P_{r_{m b}}, \%$ & $r_{m i}, \mathrm{~nm}$ & $P_{r_{m i}} \%$ \\
\hline U_484_C & 8.4353 & 29.09 & 0.05250 & 42.99 & 0.17080 & 27.89 \\
U_604_A & 8.0877 & 37.58 & 0.05363 & 44.13 & 0.21749 & 17.60 \\
U_620_C & 8.4754 & 32.74 & 0.05432 & 42.51 & 0.18261 & 24.75 \\
\hline
\end{tabular}




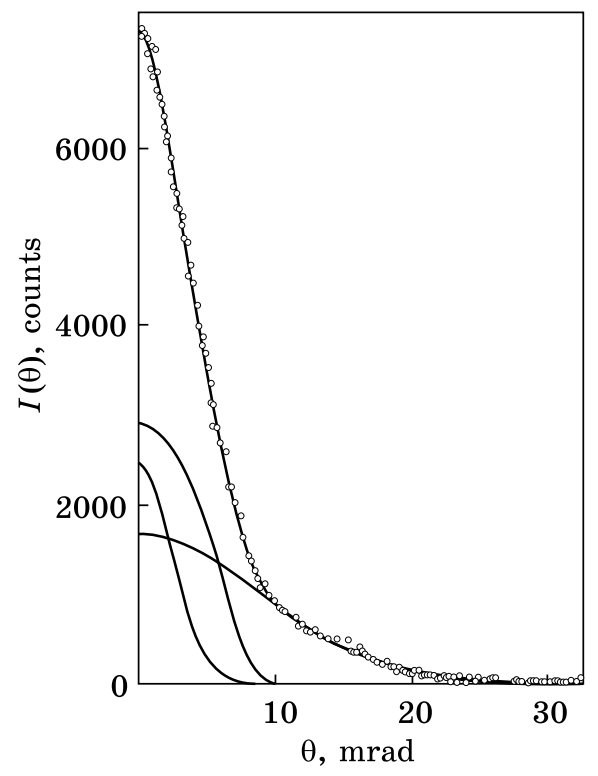

Fig. 8. Spectrum of the ACAR in highly defective MWCNTs, sample U_604_A [53]

bes of $40-60 \mathrm{~nm}$ thick of the PM series (Table 4), consisting on average of 10 carbon layers with an internal cavity diameter of $33-53 \mathrm{~nm}$, were obtained by matrix synthesis by dichloromethane pyrolysis on $\mathrm{Al}_{2} \mathrm{O}_{3}$ membranes [55]. Multilayer nanotubes with a diameter of 20$40 \mathrm{~nm}$, which contain the highest concentration of defects (U series, Table 3), were obtained by catalytic pyrolysis.

The comparison with the parameters of massive samples of reactor bulk graphite (BG), powder (PG) and

thermally expanded graphite (TEG), amorphous carbon (AC) was made.

The typical ACAR spectrum of single-layer and multilayer CNTs are presented on Figs. 7 and 8. After special cleaning, only semiconductor tubes remained in single-walled CNTs, and, accordingly, the parabolic part of the ACAR was not observed. One can observe a parabolic contribution to the ACAR in multilayer CNTs as well as in various modifications of graphite (thermally expanded, powder, monolithic ones, etc.). It can be seen from Fig. 8 and Table 3 that, in strongly defective samples of the $\mathrm{U}$ series, this contribution is greater than in weakly defective MWCNTs and graphites. The anomalously large $r_{m i}$ value for sample $\mathrm{U} 604 \mathrm{~A}$ corresponds to the double interlayer distance, which is a differential characteristic of a dislocation, i.e., the double interlayer distance, and the increased density of free electrons.

In a special series of wet MWCNTs [53], the 4-component ACAR spectra were observed with an ultra-narrow Gaussian component caused by annihilation of positrons from the state of ortho-positronium in freespace pores. Just as at the measurement of the LTP in Refs. [51, 52], where the LTP radius, $R$, varies from 1.6 to $2.6 \mathrm{~nm}$ (Table 5) according to the Tao model [23]. By using the radii $R$ of free volumes obtained from the ACAR spectra, it could be estimated (within the framework of the Tao model [23]) the LTP in these volumes and could be obtained a good numerical agreement with the experimentally measured LTPs in Refs. [51, 52]. Moreover, even the annihilation contributions from the state of ortho-positronium obtained by different methods (LTP and ACAR) for the MWCNTs (synthesized by various methods) do not differ very much [51-53]. Therefore, the nanopores found in Ref. [53] are 


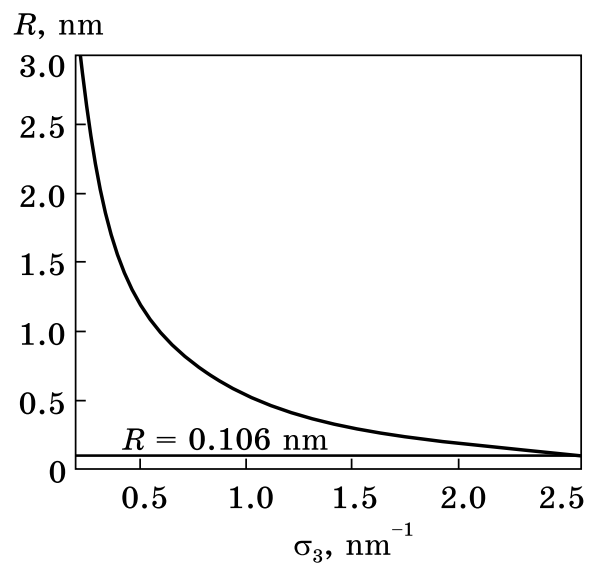

Fig. 9. Dependence of the free volume radius $R\left(\sigma_{3}\right)$ on the dispersion $\sigma_{3}$ of the ultra-narrow Gaussian of ACAR within the framework of the Tao model [23]

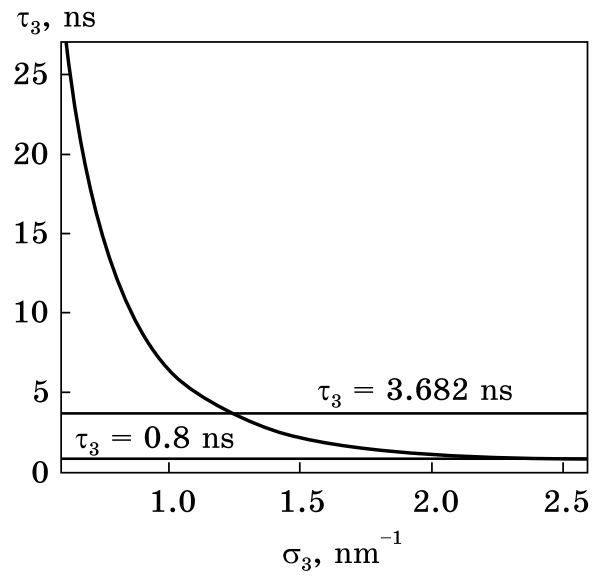

Fig. 10. Dependence of the ortho-positronium lifetime $\tau_{3}\left(\sigma_{3}\right)$ on the dispersion $\sigma_{3}$ of the ultra-narrow Gaussian of the ACAR within the framework of the Tao model [23]

most likely not a consequence of formation of the ortho-positronium state in the water remaining in wet MWCNTs, but particularly a consequence of formation of free volumes in the intertube regions, since MWCNTs were without water in Refs. [51, 52], and annihilation from the state of ortho-positronium was observed. Actually, in the case of ideal MWCNTs [50], the long-lived components of the LTP and ultranarrow Gaussian $\sigma_{3}$ in the ACAR spectrum should not be observed. However, the 'twisting' of nanotubes and the formation of bundles are caused by defects that results to the appearance of a large number of dangling bonds in the interphase (intertube) regions. These dangling bonds can polarize the positron to ortho-positronium form.

Within the framework of the Tao model [23], one can redefine $R$ and $\tau_{3}$ by the $\sigma_{3}$, i.e. the dispersion of the ultra-narrow component of the ACAR (Figs 9, 10).

From the dependence $R\left(\sigma_{3}\right)$, it could be obtained the maximum value of $\sigma_{3}$, at which the Tao model works; it is of approximately $2.5 \mathrm{~nm}^{-1}$ (for high values of $\sigma_{3}$, the Tao model gives $R$ values less than the orthopositronium radius of $0.106 \mathrm{~nm}$ ). On the dependence $\tau_{3}\left(\sigma_{3}\right)$ (Fig. 10), it is the minimum known as measured ortho-positronium lifetime equal to $0.8 \mathrm{~ns}$. The highest ortho-positronium lifetime known in the literature [51] is of $3.682 \mathrm{~ns}$. The corresponding $R$ or $\sigma_{3}$ values lie in this orthopositronium lifetime interval (0.8-3.682 ns).

The main part of positrons annihilates with $\pi$-electrons with a localization radius (of $0.11-0.25 \mathrm{~nm}$ ) in the wide interlayer spaces of CNTs, where the Van der Waals forces act. These processes, as shown above 

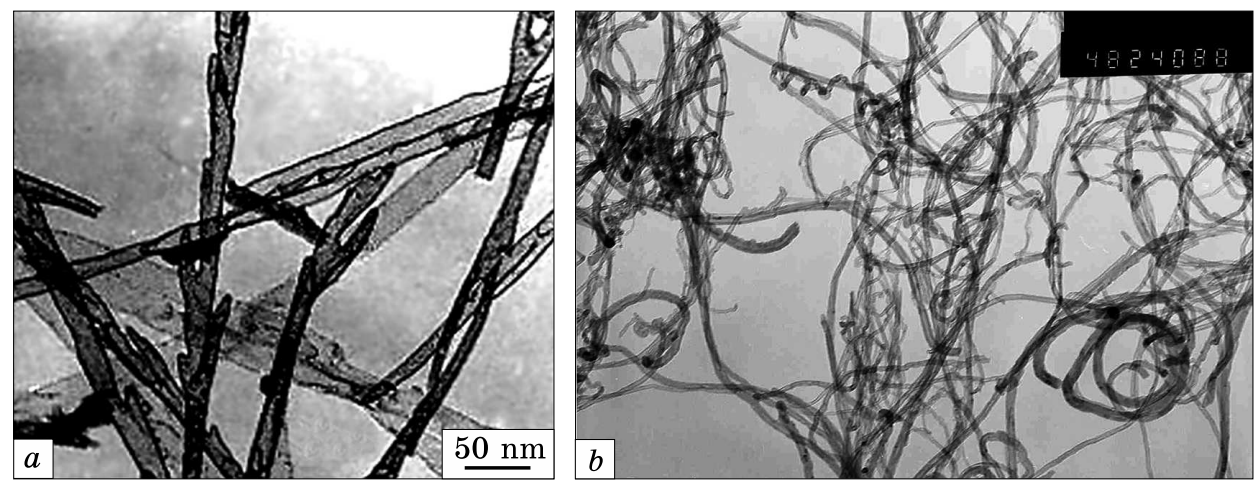

Fig. 11. Electron-microscopy images of CNTs with the smallest ( $a$ - straight CNTs) and greatest ( $b-\mathrm{U}$ series) defects [53]

Table 4. Results of decoding the parameters of the ACAR spectra of PM Series (multilayer straight), No. 13 (purified) and graphites [53]

\begin{tabular}{|l|c|c|c|c|c|l|}
\hline \multicolumn{1}{|c|}{ Sample } & $\theta_{F}, \mathrm{mrad}$ & $P_{\theta_{F}}, \%$ & $r_{m b}, \mathrm{~nm}$ & $P_{r_{m b}}, \%$ & $r_{m i}, \mathrm{~nm}$ & $P_{r_{m i}}, \%$ \\
\hline SWCNT direct & - & - & 0.0560 & 8.00 & 0.1130 & 92.00 \\
SWCNT semicond. & - & - & 0.0485 & 1.80 & 0.1158 & 98.20 \\
MWCNT spiral & - & - & 0.0501 & 10.00 & 0.1090 & 90.00 \\
MWCNT dir. 1 & 7.394 & 9.00 & 0.0493 & 13.50 & 0.1204 & 77.50 \\
MWCNT dir. 2 & 7.733 & 13.30 & 0.0680 & 29.50 & 0.1318 & 57.20 \\
MWCNT dir. 3 & 8.946 & 17.20 & 0.0539 & 41.60 & 0.1510 & 41.20 \\
MWCNT No. 13-1 & 7.339 & 13.70 & 0.0667 & 27.70 & 0.1287 & 58.60 \\
MWCNT No. 13-2 & 7.661 & 13.70 & 0.0537 & 35.30 & 0.1290 & 51.00 \\
MWCNT No. 13-3 & 7.922 & 14.30 & 0.0551 & 35.90 & 0.1310 & 49.80 \\
MWCNT No. 13-4 & 8.551 & 13.80 & 0.0627 & 22.80 & 0.1319 & 63.40 \\
MWCNT No. 13-5 & 8.513 & 12.00 & 0.0645 & 21.30 & 0.1320 & 66.70 \\
CARBON crystal & 7.519 & 25.80 & 0.0542 & 28.40 & 0.1213 & 45.8 \\
CARBON amorph. & 7.891 & 18.50 & 0.0503 & 23.40 & 0.1189 & 58.10 \\
CARBON powder & 8.052 & 18.10 & 0.0540 & 29.10 & 0.1255 & 52.80 \\
CARBON therm. ext. & 7.624 & 14.00 & 0.0582 & 18.50 & 0.1254 & 67.5 \\
\hline
\end{tabular}

Table 5. Results of decoding the parameters of the ACAR spectra of CNT_Wet Series (with water)

\begin{tabular}{|c|r|r|r|r|r|r|r|c|}
\hline Sample & $\theta_{F}, \operatorname{mrad}$ & \multicolumn{1}{|c|}{$P_{\theta_{F}}, \%$} & $r_{m b}, \mathrm{~nm}$ & $P_{r_{m b}}, \%$ & $r_{m i}, \mathrm{~nm}$ & $P_{r_{m i}}, \%$ & $R, \mathrm{~nm}$ & $P_{R}, \%$ \\
\hline CNT_W_0 & 9.5582 & 6.6252 & 0.0527 & 29.4790 & 0.1272 & 60.8540 & 1.5982 & 3.0416 \\
CNT_W_1 & 8.7957 & 6.8239 & 0.0511 & 28.4560 & 0.1231 & 62.0850 & 2.3892 & 2.6345 \\
CNT_W_2 & 10.3110 & 10.5110 & 0.0530 & 29.4000 & 0.1323 & 57.7080 & 1.8280 & 2.3811 \\
CNT_W_3 & 8.3880 & 19.6300 & 0.0543 & 30.1120 & 0.1316 & 47.6140 & 1.5770 & 2.6440 \\
CNT_W_4 & 9.3567 & 16.9620 & 0.0559 & 33.1890 & 0.1381 & 47.3210 & 2.1989 & 2.5279 \\
\hline
\end{tabular}


Fig. 12. Probability of annihilation of positrons with almost free electrons vs. the interlayer distance in CNTs and various graphite modifications
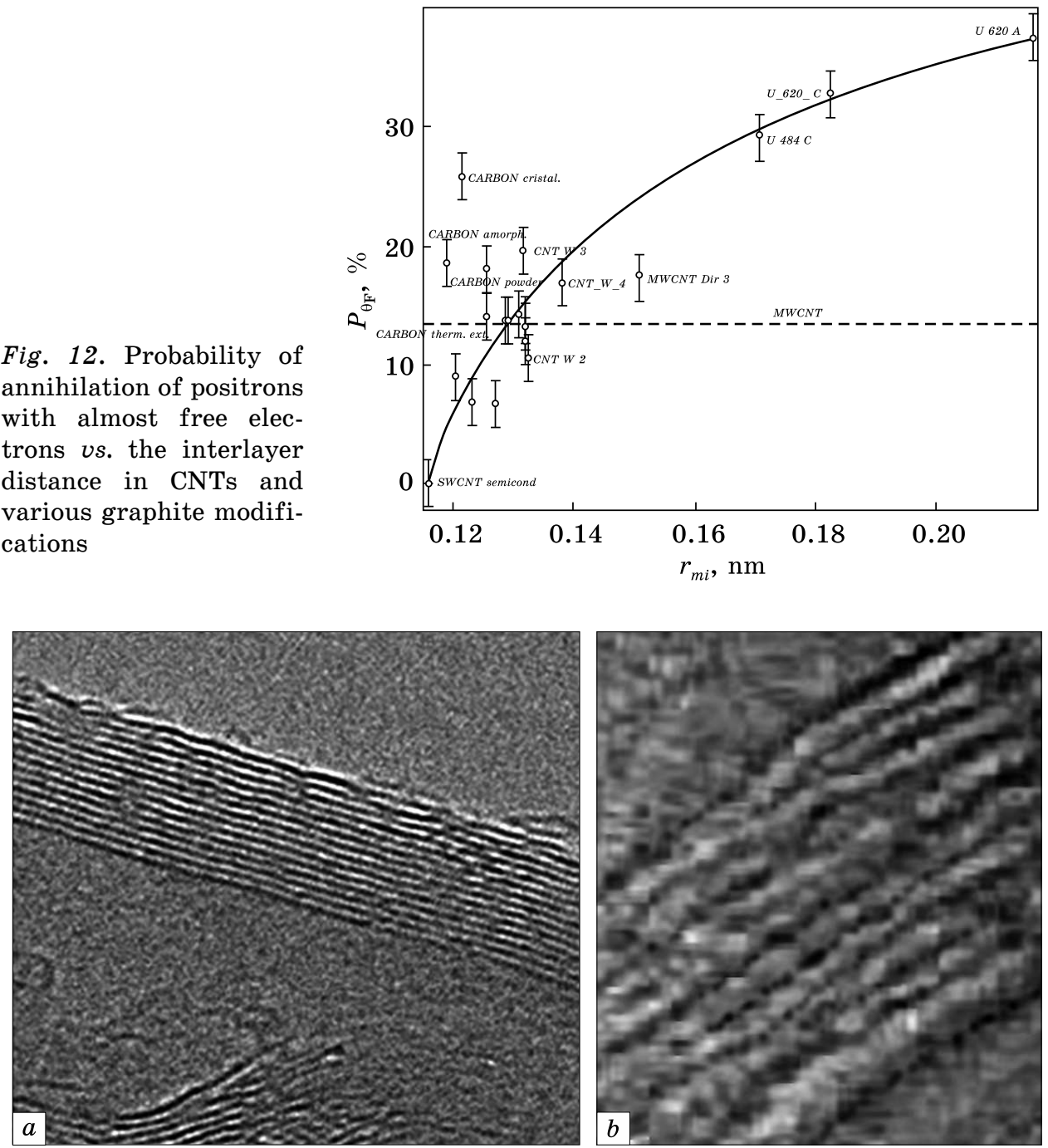

Fig. 13. Electron microscopic images of multilayer CNTs: carbon layers in a sample of series No. $13(a)$, defective carbon layers and an edge dislocation at the top in sample U_604_A $(b)$. (The scale mark in both pictures is the interlayer distance of $0.35 \mathrm{~nm})[53]$

and in Ref. [53], contribute to the narrow Gaussian. The remaining positrons annihilate with electrons of covalent unsaturated $\sigma$-bonds in the region of atomic size defects with a localization radius of $\approx 0.05 \mathrm{~nm}$ and contribute to a wide Gaussian. Figure 11 contains electron-microscopy images of straight CNTs with a small number of layers (Fig. 11, a) as well as bent and twisted into complex shapes nanotubes No. 1 (Fig. 11, $b$ ). It emerged that the latter have the greatest degree of defectiveness. 


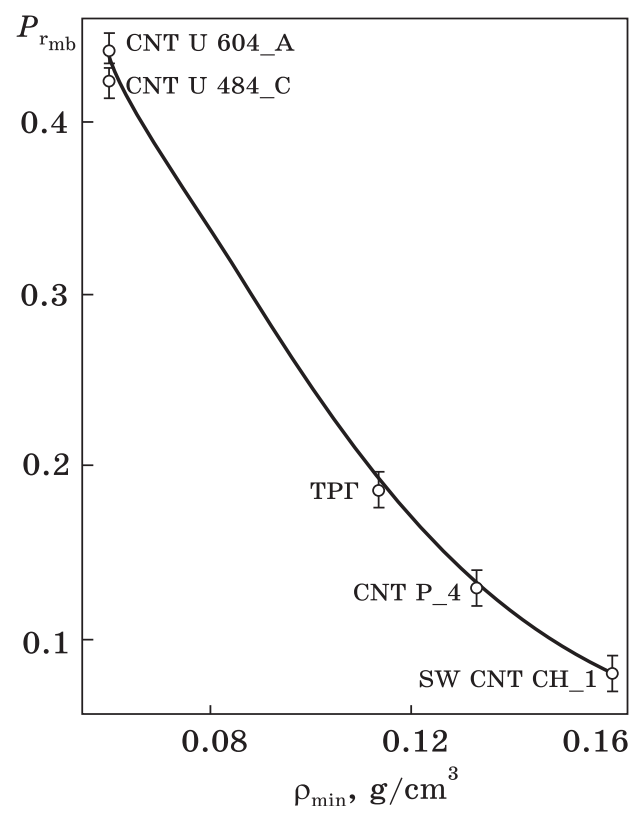

Fig. 14. Dependence of the probability of positron annihilation with defects in CNTs, MWCNTs, and thermally expanded graphite (TEG) on their average bulk density

For straight and twisted samples, the areas under the wide Gaussian are of $1.8 \%$ and $44 \%$, respectively. This is indicated on a deviation of the shape of nanotubes with defects from a straight line.

Tables 3-5 show that the radius of localization of the electron wave function in the defect region $\left(r_{m b}\right)$ for various nanotubes varies from 0.049 to $0.068 \pm 0.002 \mathrm{~nm}$. In this case, the probabilities of annihilation of positrons with electrons $P r_{m b}$ in the indicated region of defects vary from $1.8 \%$ (for straight semiconductor) to $44 \%$ (for the most defective ones). High defectiveness of MWCNTs is caused by nonequilibrium conditions of their formation [55]. It follows from the Tables that single-layer and straight multilayer CNTs obtained by the matrix method differ from others by more perfect structure, since they contain fewer defects. Obviously, in ideal (defect-free) semiconductor nanotubes, the probability of annihilation of positrons $P_{r_{m b}}$ in defects tends to zero, and the spectrum will consist of only one narrow Gaussian.

Figure 12 shows the dependence of the probability of annihilation of positrons with almost free $\pi$-electrons $P_{\theta_{F}}$ on the localization radius $r_{m i}$ of the wave function of $\pi$-electrons. The data for a large array of CNTs differing in the conditions of production are presented. It can be seen that the larger value of $r_{m i}$ corresponds to the greater value of $P_{\theta_{F}}$. For comparison, data for thermally expanded (TEG), amorphous (AG), powder (PG), and crystalline (CG) graphites are plotted on the graph. As appeared, the points for all CNTs including the TEG (but except for AG, PG and CG) are situated on the smooth curve $r_{m i}=f\left(P_{\theta_{F}}\right)$. This means that, with an increase in the radius of localization of the wave function of electrons between the carbon layers $\left(r_{m i}\right)$, the area under the wide Gaussian $\left(P_{r_{m b}}\right)$ increases; it means that the number of defects (Tables $3-5$ ) and the relative fraction of nearly free electrons $P_{\theta_{F}}$ increase (Fig. 12).

It follows that, with an increase in the concentration of defects, the electrons transition from a localized state (narrow Gaussian) to a deloca- 
Fig. 15. Dependences of the electronic structure parameters $r_{m b}$ and rmi on the probability of annihilation of positrons with almost free electrons in CNTs and various graphite modifications (data are taken from Tables $3-5$ [53])

lized free (or quasi-free) state (parabola) occurred. The latter behave like conduction electrons, as evidenced by an increase in electrical conductivity. The value of the $r_{m i}$ parameter varies in an unusually wide range and reaches a maximum value of $0.248 \mathrm{~nm}$ for the most defective MWNTs U 604 A. This is almost twice as much as the typical value $(\approx 0.13 \mathrm{~nm})$ for MWCNTs of series No. 13. It can be assumed that, in this case, positrons are captured by defects of a large size equal to twice-interlayer distance. These defects can primarily be attributed to edge dislocations. The radius of localization of electrons within them is comparable with the radius of the core of the dislocation. Transmission electron microscopy studies with the resolution of individual graphene layers shown in orderly arranged carbon hexagonal layers with a distance between them of $0.35 \mathrm{~nm}$ are visible in Fig. 13, $a$. In Figure 13, $b$, with even higher magnification, an edge dislocation is seen against the background of defective graphene layers in the form of layer breaks. The free volume region formed by the edge dislocation has a wedge profile with a maximum size equal to approximately twice-interlayer distance $(0.5-0.6 \mathrm{~nm})$.

The appearance of an edge dislocation leads to the breaking of covalent $\sigma$-bonds at the edge of the layer in the core of the dislocation. This means that the wave functions of dangling (unsaturated) bonds will overlap with the wave functions of the extended $\pi$-bonds. Indeed, as shown in Ref. [56], unsaturated $\sigma$-bonds cause an increase in the overlap of electron wave functions and, therefore, can lead to hybridization of $\pi$ - and $\sigma$-electrons. Obviously, such hybridization takes place in this case.

It is important to note the dependence of parameter of the electronic structure of CNTs $\operatorname{Pr}_{m b}$ (the probability of annihilation of positrons in defects) on the integral characteristic of the MWNT array, namely, the average minimum density, at which the MWNT array be- 
gins to conduct (Fig. 14). As Figure 14 demonstrates, the most defective CNTs begin conduct at minimum density (compression ratio).

Figure 15 shows the dependences of the electronic-structure parameters $r_{m b}$ and $r_{m i}$ on the probability of annihilation of positrons with almost free electrons in all the MWCNTs and various graphite modifications we studied.

From Tables 3-5 and Fig. 15, we can establish as follow.

- The average value of the parameter that is determining the wall thickness of the nanotube is $r_{m b}=0.0535 \mathrm{~nm}$; this parameter changes in the range $0.0493 \leq r_{m b} \leq 0.0680 \mathrm{~nm}$. The values of the parameter $r_{m b}$ above the average are observed in a narrow range of probabilities of positrons annihilation with almost free electrons $P_{\theta_{F}}$ in CNTs near the characteristic value of $13.7 \%$.

- The average value of the parameter determining the interlayer distance of the nanotube is $r_{m i}=0.132 \mathrm{~nm}$; it changes within the range $0.1204 \leq r_{m i} \leq 0.2175 \mathrm{~nm}$. In the studied set of strongly defective samples of the U series with the largest values of $r_{m i}$ and $P_{\theta_{F}}$, an increase of $r_{m i}$ is observed with an increase of $P_{\theta_{F}}$.

- Corresponding to the Fermi momentum, values of the parameter $\theta_{F}$ of the ACAR form are in the range $7.293 \leq \theta_{F} \leq 10.311 \mathrm{mrad}$.

- The probabilities of annihilation of positrons with almost free electrons $P_{\theta_{F}}$ in CNTs are within interval $6.63 \% \leq P_{\theta_{F}} \leq 37.58 \%$.

\section{Summary and Conclusions}

Based on the foregoing, it is clear that positron spectroscopy is unique and one of the most informative non-destructive methods for diagnostics of the electronic structure and electronic properties of various classes of materials, including perspective carbon nanomaterials. Summarizing the results of applying this method to carbon nanotubes, we can state the following.

(i) The annihilation of positrons in carbon nanotubes occurs: (1) with $\pi$-electrons in the interlayer spaces (narrow Gaussian); (2) with electrons of unsaturated covalent $\sigma$-bonds in the region of structural defects of the hexagonal layer (wide Gaussian); (3) with quasi-free conduction $\pi$-electrons, which give a parabolic contribution to the distribution of electrons by momenta.

(ii) The ACAR spectrum of semiconductor single-walled CNTs is a superposition of two Gaussians. The absence of a parabolic component indicates the absence of quasi-free electrons in single-walled nanotubes according to EPA.

(iii) With an increase in the localization radius of the wave function of $\pi$-electrons in the interlayer spaces, the fraction of free electrons in CNTs increases. 
(iv) A twofold increase in the localization radius of the wave functions of $\pi$-electrons is associated with the appearance of edge dislocations and is accompanied by a sharp increase in the parabolic contribution from quasi-free electrons to the ACAR spectrum, which is caused by increased overlap of electron wave functions during hybridization of unsaturated $\sigma$-bonds and stretched $\pi$-bonds.

(v) In a series of wet samples, annihilation from the ortho-positronium state with characteristic sizes of free volume effective pore radii of 1.6-2.4 $\mathrm{nm}$ was established.

(vi) The high sensitivity of positrons to defects can be used to deelop methods for certification of MWCNTs and identification of defects: values of $2 r_{m b}, 2 r_{m i}$, and $R$ obtained from the ACAR are the layer thickness, the interlayer distance, and the effective radius of free volume of MWCNTs, respectively.

Acknowledgements. The authors are grateful to Prof. Evgen G. Len for discussion and support of the article. The paper contains some ideas and results acting as a background of the scientific project 'Complex diagnostics of sensitive to strains and defects structural and electronic properties of metallic nanomaterials' (state registration number 0120U102265) within the framework of the goal-oriented program of fundamental research of the NAS of Ukraine 'Prospective fundamental research and innovative development of nanomaterials for the needs of industry, health care, and agriculture' for 2020-2024 (proposal No. $1.5 / 10$ as of 05.03 .2020 and agreement No. $22 / 20-\mathrm{H}$ as from 16.04.2020).

\section{REFERENCES}

1. P.A.M. Dirac, Math. Proc. Camb. Philos. Soc., 26, Iss. 3: 361 (1930). https://doi.org/10.1017/S0305004100016091

2. C.D. Anderson, Phys. Rev., 43, Iss. 6: 491 (1933). https://doi.org/10.1103/PhysRev.43.491

3. M. Deutsch, Phys. Rev., 83: 866 (1951)

4. S. Berko and J.S. Plaskett, Phys. Rev., 112, Iss. 6: 1877 (1958). https://doi.org/10.1103/PhysRev.112.1877

5. S. Berko, Phys. Rev., 128, Iss. 5: 2166 (1962). https://doi.org/10.1103/PhysRev.128.2166

6. I.Ya. Dekhtyar and V.S. Mikhalenkov, Doklady Akad. Nauk SSSR, 140: 1293 (1961) (in Russian).

7. Positrons in Solids (Ed. P. Hautojarvi). Topics in Current Physics (Berlin-Heidelberg: Springer: 1979), vol. 12. https://doi.org/10.1007/978-3-642-81316-0

8. M. Eldrup, D. Lightbody, and J.N. Sherwood, Chem. Phys., 63, Iss. 1-2: 51 (1981). https://doi.org/10.1016/0301-0104(81)80307-2

9. Positron and Positronium Chemistry (Eds. D.M. Schrader and Y.C. Jean). Studies in Physical and Theoretical Chemistry (Amsterdam-Oxford-New York-Tokyo: Elsevier: 1988), vol. 57. 
10. Y.C. Jean, Microchemical Journal, 42, Iss. 1: 72 (1990). https://doi.org/10.1016/0026-265X(90)90027-3

11. O.E. Mogensen, Positron Annihilation Chemistry. Springer Series in Chemical Physics (Berlin: Springer-Verlag: 1995), vol. 58, p. 15. https://doi.org/10.1007/978-3-642-85123-0_2

12. R.A. Pethrick, Prog. Polym. Sci., 22: 1 (1997). https://doi.org/10.1016/S0079-6700(96)00023-8

13. G. Dlubek, F. Börner, R. Buchhold, K. Sahre, R. Krause-Rehberg, and K.-J. Eichhorn, J. Polym. Sci., Part B: Polym. Phys., 38: 3062 (2000). https://doi.org/10.1002/1099-0488(20001201)38:23\%3C3062::AIDPOLB80\% 3E3.0.CO;2-I

14. K.G. Lynn, J.R. MacDonald, R.A. Boie, L.C. Feldman, J.D. Gabbe, M.F. Robbins, E. Bonderup, and J. Golovchenko, Phys. Rev. Lett., 38, Iss. 5: 241 (1977). https://doi.org/10.1103/PhysRevLett.38.241

15. A. Dupasquier and A.P. Mills, Positron Spectroscopy of Solids (Amsterdam: ISPress: 1993).

16. R.A. Ferrell, Rev. Mod. Phys., 28, Iss. 3: 308 (1956). https://doi.org/10.1103/RevModPhys.28.308

17. M.M. Nyshchenko, E.A. Tsapko, V.Yu. Koda, V.S. Mykhalenkov, G.P. Prykhod'ko, Yu.I. Sementsov, R.V. Mazurenko, and S.M. Makhno, Metallofiz. Noveishie Tekhnol., 35, No. 9: 1167 (2013) (in Ukranian).

18. J.P. Carbotte, Phys. Rev., 144, Iss. 1: 309 (1966). https://doi.org/10.1103/PhysRev.144.309

19. D. Hudson, Statistika dlya Fizikov [Statistics for Physicists] (Moscow: Mir: 1987) (Russian translation).

20. V.S. Mikhalenkov, Phys. Status Solidi A, 24, Iss. 2: 107 (1974). https://doi.org/10.1002/pssa.2210240245

21. A. Cizek, F. Parizek, J. Adam, I.Ya. Dekhtyar, and V.S. Mikhalenkov, Czech. J. Phys. B, 19, 5: 629 (1969).

https://doi.org/10.1007/BF01691476

22. Y.C. Jean, J.D. Van Horn, W.S. Hung, and K.R. Lee, Macromolecules, 46, 18: 7133 (2013).

https://doi.org/10.1021/ma401309x

23. S.J.J. Tao, Chem. Phys., 56, Iss. 11: 5499 (1972). https://doi.org/10.1063/1.1677067

24. D. Singh, W.E. Pickett, R.E. Cohen, H. Krakauer, and S. Berko, Phys. Rev. B, 39, Iss. 13: 9667(R) (1989). https://doi.org/10.1103/PhysRevB.39.9667

25. M. Peter and A.A. Manuel, Physica Scripta, 1989, T29: 106 (1989). https://doi.org/10.1088/0031-8949/1989/T29/019

26. P.E. Mijnarends and A. Bansil, Positron Spectroscopy of Solids (Eds. A. Dupasquier and A.P. Mills Jr.). Proceedings of the International School of Physics 'Enrico Fermi' (1995), vol. 125, p. 25. https://doi.org/10.3254/978-1-61499-211-0-25

27. R. Zhang, H. Cao, H.M. Chen, P. Mallon, T.C. Sandreczk, J.R. Richardson, Y. C. Jean, B. Nielsen, R. Suzuki, and T. Ohdaira Radiat. Phys. Chem., 58, Iss. 5-6: 639 (2000). https://doi.org/10.1016/S0969-806X(00)00235-8

28. W.-S. Hung (Thesis of Disser. for Ph.D. in Chemical Engineering) (Chungli, Taiwan: Chung-Yuan Christian University: 2011).

29. E. Nascimento, O. Helene, C. Takiya, and V.R. Vanin, Nucl. Instrum. Methods Phys. Res. Sect. A, 538, Iss. 1-3: 723 (2005). https://doi.org/10.1016/j.nima.2004.09.013 
30. E. Bonderup, J.U. Andersen, and D.N. Lowy, Phys. Rev. B, 20: 883 (1979). https://doi.org/10.1103/PhysRevB.20.883

31. M. Sob, J. Phys. F: Met. Phys., 15, No. 8: 1685 (1985). https://doi.org/10.1088/0305-4608/15/8/008

32. M. Barbiellini, M. Hakala, J. Puska, R.M. Nieminen, and A.A. Manueli, Phys. Rev. B, 56, Iss. 12: 7136 (1997). https://doi.org/10.1103/PhysRevB.56.7136

33. A. Seeger, J. Phys. F: Met. Phys., 3, No. 2: 248 (1973). https://doi.org/10.1088/0305-4608/3/2/003

34. M. Doyama and R. Hasiguyi, Cryst. Lattice Defects, 4: 139 (1973).

35. I.Ya. Dekhtyar, Phys. Rep., 9, Iss. 5: 243 (1974). https://doi.org/10.1016/0370-1573(74)90021-0

36. R.N. West, Adv. Phys., 22, Iss. 3: 263 (1973). https://doi.org/10.1080/00018737300101299

37. V.S. Mikhalenkov, V.I. Tokar, and E.A. Tsapko, Metallofiz. Noveishie Tekhnol., 7, No. 5: 101 (1985) (in Russian).

38. D.G. Lock and R.N. West, J. Phys. F: Met. Phys., 4, No. 12: 2179 (1974). https://doi.org/10.1088/0305-4608/4/12/014

39. P. Kubica, B.T.A. McKee, A.T. Stewart, and M.J. Stott, Phys. Rev. B, 11, Iss. 1: 11 (1975). https://doi.org/10.1103/PhysRevB.11.11

40. M.J. Stott and P. Kubica, Phys. Rev. B, 11, Iss. 1: 1 (1975). https://doi.org/10.1103/PhysRevB.11.1

41. I.M. Hong and J.P. Carbotte, Can. J. Phys., 55, No. 15: 1335 (1977). https://doi.org/10.1139/p77-170

42. V.S. Mikhalenkov, V.I. Tokar, and E.A. Tsapko, Ukr. J. Phys., 24, No. 10: 1552 (1979) (in Russian).

43. A.P. Cracknell, The Fermi Surfaces of Metal (London: Taylor and Francis Ltd.: 1971).

44. V.S. Mikhalenkov, V.I. Tokar, and E.A. Tsapko, Proc. $5^{\text {th }}$ Int. Conf. Positron Annihilation (Lake Yamanaka, Japan, April 1979) (Sendai, Japan: The Japan Institute of Metals: 1979).

45. M.J. Puska, P. Lanki, and R.M. Nieminen, J. Phys.: Condens. Matter, 1, No. 35: 6081 (1989). https://doi.org/10.1088/0953-8984/1/35/008

46. P. Kirkegaard and M. Eldrup, Comp. Phys. Comm., 3, Iss. 3: 240 (1972). https://doi.org/10.1016/0010-4655(72)90070-7

47. P. Kirkegaard and M. Eldrup, Comp. Phys. Comm., 7, Iss. 7: 401 (1974). https://doi.org/10.1016/0010-4655(74)90070-8

48. C.J. Virtue, R.J. Douglas, and B.T.A. McKee, Comp. Phys. Comm., 15, Iss. 1-2: 97 (1978). https://doi.org/10.1016/0010-4655(78)90084-X

49. P. Kirkegaard, J.V. Olsen, M. Eldrup, and N.J. Pedersen, Riso DTU (Denmark: National Laboratory for Suntainable Energy: 2009).

50. Sh. Ishibashi, J. Phys.: Condens. Matter, 14, No. 41: 9753 (2002). https://doi.org/10.1088/0953-8984/14/41/330

51. A.T. Luu, Zs. Kajcsos, N.D. Thanh, T.Q. Dung, M.V. Nhon, K. Lazar, K. Havancsak, G. Huhn, Z.E. Horvath, T.D. Tap, L.T. Son, and P.T. Phuc, Phys. Status Solidi C, 6, Iss. 11: 2578 (2009). https://doi.org/10.1002/pssc.200982105

52. M. Xing-kun, C. Hong, H. Yuan-jin, Y. Nagashima, H. Saito, and T. Hyodo, Acta Physica Sinica, 8, No. 10: 783 (1999). https://doi.org/10.1088/1004-423X/8/10/008 
53. M.M. Nishchenko, E.A. Tsapko, Yu.V. Lisunova, G.P. Prikhod'ko, and N.I. Danilenko, Inorganic Materials: Applied Research, 2, No. 2: 186 (2011). https://doi.org/10.1134/S2075113311020158

54. R.S. Justice, D.H. Wang, L.-S. Tana, and D. W. Schaefer, J. Appl. Cryst., 40: s88 (2007). https://doi.org/10.1107/S0021889807004153

55. V.Yu. Koda, M.M. Nishchenko, A.V. Brichka, S.Ya. Brichka, and G.P. Prikhod'ko, Nanosistemi, Nanomateriali, Nanotehnologii, 3, No. 1: 227 (2005).

56. R.K. Mueller and K.N. Maffitt, J. Appl. Phys., 35, Iss. 3: 734 (1964). https://doi.org/10.1063/1.1713456

Received 16.04.2020;

in final version, 14.05.2020

Є.А. Цапко, І.Є. Галстян

Інститут металофізики ім. Г.В. Курдюмова НАН України, бульв. Академіка Вернадського, 36,

03142 Київ, Україна

ДОСЛІДЖЕННЯ СТРУКТУРНИХ ДЕФЕКТІВ

І ЕЛЕКТРОННИХ ВЛАСТИВОСТЕЙ ВУГЛЕЦЕВИХ

НАНОТРУБОК МЕТОДОМ ПОЗИТРОННОЇ СПЕКТРОСКОПІЇ

У роботі розглянуто переваги та недоліки різних методів позитронної спектроскопії у вивченні електронних властивостей багатошарових вуглецевих нанотрубок (БВНТ) із металевим і напівпровідниковим типами провідности. Методом кутової кореляції анігіляційного випромінення (ККАВ) установлено вплив дефектів на параметри електронної структури БВНТ. Аналіз результатів показав, що анігіляція відбувається з б-електронами (у міжшарових проміжках), із квазивільними електронами та з електронами ненасичених ковалентних зв'язків. Показано, що зростання концентрації дефектів спричинює збільшення радіуса локалізації хвильової функції електронів $\left(r_{m 1}\right)$ у міжшарових проміжках і зростання частки квазивільних електронів. Унаслідок утворення крайових дислокацій у БВНТ відбуваються подвоєння $r_{m 1}$ (до 0,25 нм), гібридизація ненасичених і розтягнутих $\sigma$-зв'язків i, як наслідок, зростання концентрації електронів провідности. Висока чутливість позитронів до дефектів може бути використана для розробки методів атестації БВНТ й ідентифікації дефектів; величини $2 r_{m b}, 2 r_{m i}$ та $R$, одержані зі спектрів ККАВ, $\epsilon$, відповідно, товщиною шару, міжшаровою віддаллю й ефективним радіусом вільного об'єму БВНТ.

Ключові слова: позитронна спектроскопія, вуглецеві нанотрубки, дефекти структури, радіус локалізації хвильової функції, електронні властивості.

\section{Е.А. Цапко, И.Е. Галстян}

Институт металлофизики им. Г.В. Курдюмова НАН Украины, бульв. Академика Вернадского, 36,

03142 Киев, Украина

ИССЛЕДОВАНИЕ СТРУКТУРНЫХ ДЕФЕКТОВ

И ЭЛЕКТРОННЫХ СВОЙСТВ УГЛЕРОДНЫХ

НАНОТРУБОК МЕТОДОМ ПОЗИТРОННОЙ СПЕКТРОСКОПИИ

В работе рассмотрены преимущества и недостатки различных методик позитронной спектроскопии в изучении электронных свойств многослойных углеродных нанотрубок (МУНТ) с металлическим и полупроводниковым типами проводимо- 
сти. Методом угловой корреляции аннигиляционного излучения (УКАИ) установлено влияние дефектов на параметры электронной структуры МУНТ. Анализ результатов показал, что аннигиляция происходит с б-электронами (в межслоевых промежутках), с квазисвободными электронами и с электронами ненасыщенных ковалентных связей. Показано, что рост концентрации дефектов приводит к увеличению радиуса локализации волновой функции электронов $\left(r_{m 1}\right)$ в межслоевых промежутках и росту доли квазисвободных электронов. Вследствие образования краевых дислокаций в МУНТ происходят удваивание $r_{m 1}$ (до 0,25 нм), гибридизация ненасыщенных и растянутых $\sigma$-связей и, как следствие, рост концентрации электронов проводимости. Высокая чувствительность позитронов к дефектам может быть использована для разработки методов аттестации МУНТ и идентификации дефектов; величины $2 r_{m b}, 2 r_{m i}$ и $R$, полученные из спектров УКАИ, являются, соответственно, толщиной слоя, межслоевым расстоянием и эффективным радиусом свободного объёма МУНТ.

Ключевые слова: позитронная спектроскопия, углеродные нанотрубки, дефекты структуры, радиус локализации волновой функции, электронные свойства. 